\title{
Proximal femur locking compression plate in complex proximal femoral fractures: a retrospective analysis
}

\author{
Rajesh Govindasamy ${ }^{1}$, Ramkumar Gnanasundaram ${ }^{2}$, Saravanan Kasirajan ${ }^{1}$, \\ Jimmy J. Meleppuram ${ }^{1}$, Kumar Archit ${ }^{1}$
}

\begin{abstract}
${ }^{1}$ Department of Orthopaedics, Vinayaka Missions medical college, Karaikal, Puducherry, India
${ }^{2}$ Department of Orthopaedics, Saveetha Medical College, Chennai, India
\end{abstract}

Received: 25 July 2016

Accepted: 29 July 2016

\author{
*Correspondence: \\ Dr. Rajesh Govind, \\ E-mail: drgrortho@yahoo.com
}

Copyright: (c) the author(s), publisher and licensee Medip Academy. This is an open-access article distributed under the terms of the Creative Commons Attribution Non-Commercial License, which permits unrestricted non-commercial use, distribution, and reproduction in any medium, provided the original work is properly cited.

\begin{abstract}
Background: Proximal femoral fractures are one of the most common fractures in old age patients. Fixation of these fractures is technically high demanding owing to the high risk of complications. The aim of our study is to analyze the outcomes of proximal femoral locking compression plate (PF-LCP) in these fractures.

Methods: We retrospectively analyzed 18 proximal femoral fractures treated with PF-LCP from May 2012 to May 2015. There were 12 females (67\%) and six males (33\%) with an average age of 59.6 years (range, 32 to 84 years). The peritrochanteric fractures constituted by intertrochanteric and subtrochanteric fractures were classified by Boyd and Griffin classification along with Seinshemier's classification, respectively. Among that, 14 cases (77\%) were of intertrochanteric and four cases $(23 \%)$ were of subtrochanteric fracture pattern. The functional outcome was evaluated by harris hip score and the parker palmer mobility score one year after surgery.

Results: Among 18 patients, 16 patients obtained fracture union without further intervention; two patients required additional bone grafting. There were no cases of hip screw cutting the femoral head. There was no post-operative mortality in our study. The average harris hip score was 85.5 (83-94). The assessment by parker and palmar mobility score was 7.6 (range 4-9).

Conclusions: The PF-LCP is a good stable alternative in the treatment of complex proximal femoral fractures. It provides good to excellent bone healing with limited complications.
\end{abstract}

Keywords: Fracture fixation, Internal, Bone plates, Pertrochanteric fractures

\section{INTRODUCTION}

Proximal femur fractures are common injuries that mostly affect the elderly population. ${ }^{1}$ In young and healthy individuals, the injury results from high energy trauma, where as in the elder age group, most of the fractures are osteoporotic, resulting from a trivial fall. Proximal femur fractures comprise, fractures of intertrochanteric and subtrochanteric region or combination of both.
Inter trochanteric fractures are common in the elderly female due to osteoporosis and $90 \%$ of fractures result from a simple fall. ${ }^{1}$ As conservative methods resulted in higher mortality rates ranging from 4.5 to $22 \%$ they are now indicated only for elderly person with high medical risk for anesthesia and surgery. ${ }^{2}$ Thus, surgery by internal fixation is the ideal choice. The aim of the surgery is to achieve initial stability and early mobilization of the patients and to avoid complications such as deep vein thrombosis, pulmonary embolism, urinary and lung 
infections and ulcers. ${ }^{2}$ Dynamic hip screw (DHS) is the gold standard treatment for stable intertrochanteric fractures. ${ }^{3}$

In case of unstable intertrochanteric fractures, the incidence of limb shortening, medialization of distal fragment and implant cutouts are high. In this case, proximal femur nail (PFN) is the implant of choice. ${ }^{4,5}$ PFN has additional anti rotation pin or set pin used to prevent the rotational strain at the fracture site. Due to the better understanding of bio-mechanics of hip fracture geometry this technique could provide better results. ${ }^{6,7}$

In certain cases, like great trochanter or lateral wall fracture type in proximal femoral fractures, PFN cannot be performed. ${ }^{8,9}$ In those cases, dynamic condylar screw (DCS) is the treatment of choice, but, if there is more communition in lateral wall, DCS is difficult to perform. ${ }^{10}$ The lateral trochanteric wall is believed to be an important factor in stabilizing pertrochanteric fractures, keeping the lateral wall intact reduces the rates of malunion and nonunion as well as can assist in fracture healing. This led to the development of newer methods like Proximal femur Locking Compression Plate (PFLCP). It is the feasible alternative for the treatment. ${ }^{11,12}$

PF-LCP provides the surgeon with the flexibility to achieve plate to bone apposition as well as axial compression or angular stability because of three screw fixation at the fracture site. Unlike conventional compression plates, the screw head locks into the PFLCP, thereby creating an angular stable construct. PFLCP can provide a stress shield for the lateral trochanteric wall and prevent lateral migration of proximal fragments. Thus, PF-LCP does not fail at the screw bone interface and provide a strong anchor in osteoporotic bone. The multiple locking screw holes of the PF-LCP provide various options to tackle complex fracture pattern. It functions as an internalized external fixator and minimizes the pressure on the periosteum and encourages biological healing. ${ }^{13}$

The aim of our study is to analyze the outcomes of PFLCP in fixation of proximal femoral fractures in terms of union, functional outcome, post-operative complications and failure rate.

\section{METHODS}

In our study, eighteen adult patients with complex proximal femur fractures following the inclusion criteria treated with PF-LCP from May 2012 to May 2015 were retrospectively analyzed. There were 12 females $(67 \%)$ and six males $(33 \%)$ with an average age of 59.6 years (range, 32 to 84 years). Most of the fractures were caused by trivial fall $(\mathrm{n}=10)$ followed by road traffic accidents $(n=8)$. The right side was included in six cases $(33 \%)$ and the left side in 12 cases $(67 \%)$. The peritrochanteric fractures constituted by intertrochanteric and subtrochanteric fractures were classified by Boyd and
Griffin classification along with Seinshemier's classification, respectively. ${ }^{14}$ Among that, 14 cases $(77 \%)$ were of intertrochanteric and four cases $(23 \%)$ were of subtrochanteric fracture pattern. All cases were followed up routinely.

\section{Inclusion criteria}

- Patients with complex proximal femur fractures

- Lateral wall fractures with comminution

- Fractures with severe osteoporosis.

\section{Exclusion criteria}

- Simple trochanteric fracture

- Femoral neck fracture

- Pathological fractures

- Non communited and Reverse oblique fracture

\section{Surgical technique}

As soon as the patient with suspected subtrochanteric or trochanteric fracture was seen, necessary clinical and radiological evaluation was done and admitted to the ward after necessary resuscitation and splintage using skin traction with adequate weights depending upon his/her built. Analgesics and antibiotics were given accordingly. Patients were evaluated for associated medical problems and cross reference was obtained from other respective departments, if required. Associated injuries were evaluated and treated simultaneously. All patients were operated on elective basis.

After adequate preoperative planning, under spinal or epidural anaesthesia, patients were positioned supine on the fracture table, reduction achieved and confirmed under image intensifier paying special attention to the posterior and medial cortical contact. A $15 \mathrm{cms}$ vertical incision was taken from the tip of trochanter in distal direction along the shaft of femur. Fascia lata was opened in line with the incision and gluteus medius and vastus lateralis muscles were split in line with the fibers and tip of the trochanter, thereby exposing the proximal femur.

The ultimate plate position and screw position depends upon fracture reduction and placement of guide wires into the femoral head and neck. The fixed-angle wire guides are threaded to the proximal three holes of the plate, and the plate is approximated to the proximal femur. Next, a guide wire was advanced through the most proximal (95degree) hole. The correct path of this wire is approximately one centimetre inferior to the piriformis fossa into the inferior femoral head on the anteroposterior (AP) view, and central in the femoral head on the lateral view. A guide wire is inserted into the next distal (120-degree) hole, and because this is in a different plane than the first hole, the surgeon must visualize its position on the lateral $x$-ray. The third guide wire, in the 135degree hole, is then placed, which is in the same plane as the first hole and may alternatively be inserted near the 
end of the procedure without compromising the stability of the construct. All three guide wires should be in subchondral bone of the femur head before inserting the screws which is confirmed by $\mathrm{C}$-arm in the AP and lateral views. The screw lengths are measured using an indirect device over the guide wires with the wire guides still attached and the appropriate, fully threaded, cannulated screws $(7.3 \mathrm{~mm}$ for the two proximal holes and $5.0 \mathrm{~mm}$ for the third proximal hole) are selected. These cannulated screws are inserted over the guide wires with the guides removed. During distal screws fixation, in subtrochantric fractures first fracture should be reduced, then fix the non-locking screws in compression mode followed by locking screws whereas intertrochantric fracture can be fixed with locking screws. After the completion of the fixation, thorough wash of the wound was given with normal saline. Suction drain was inserted at the entry point and wound closed in layers.

Post-operatively, adequate analgesics, intravenous antibiotics were given for subsequent five days. Prophylactically, in all patients, subcutaneous low molecular weight heparin (LMWH) was given for three consecutive days. Post-operative check X-ray obtained. Drain removed after 48 hours. Bedsides, knee bending exercises were initiated when pain reduced on third or fourth post-operative day. Patients were reviewed at 6 weeks, 3 months, 6 months and one year after operation with clinical and radiographic assessment for the progress of fracture healing and complication. The functional outcome was assessed by harris hip score and parker and palmer mobility score one year after the surgery. ${ }^{15}$

\section{RESULTS}

The patients were followed up for an average of 14 months (12 to 24 months). The average operating time was 50 minutes with a mean blood loss of $200 \mathrm{ml}$ (including operative and wound drainage). The average length of incision was $7 \mathrm{~cm}$ ( 5 to $9 \mathrm{~cm})$. Average image intensifier time was 10 minutes.

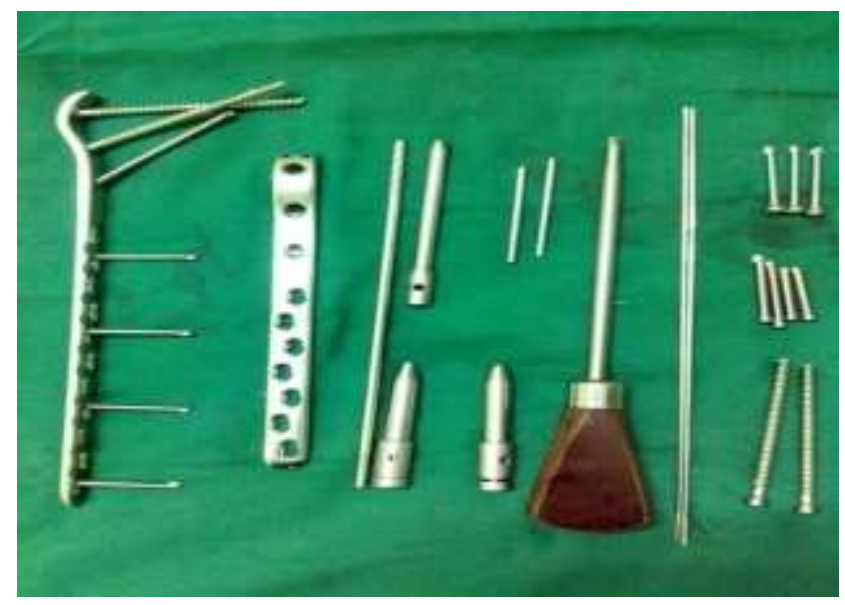

Figure 1: Proximal femur locking compression plate with screws set.

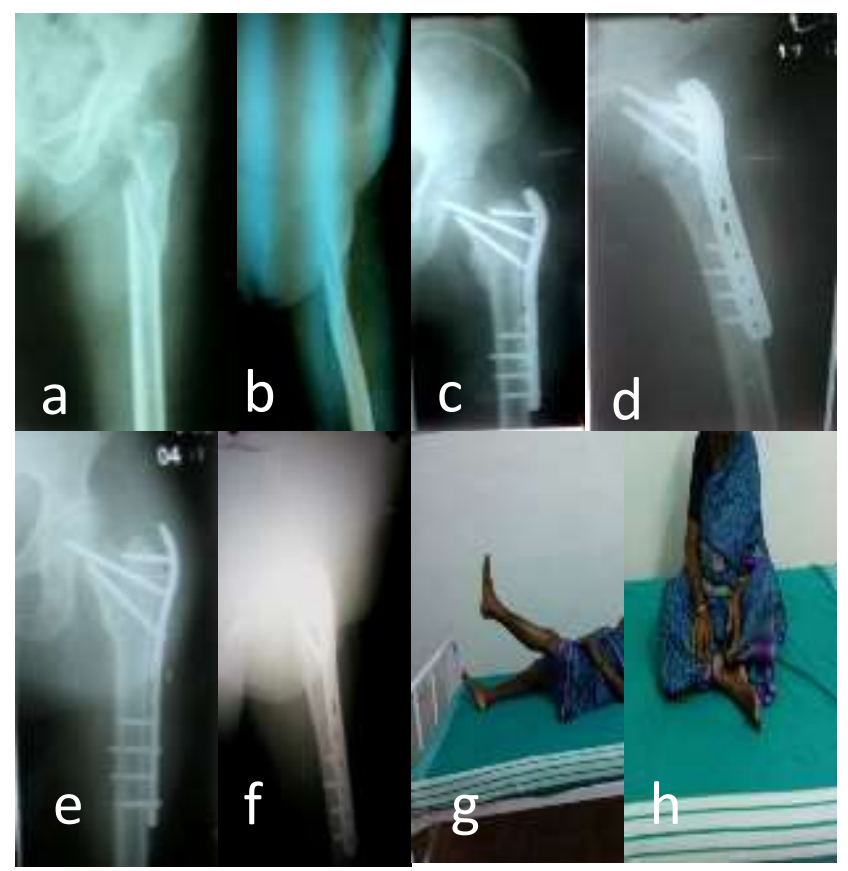

Figure 2: a,b) Pre-operative X-rays of 60 years female with left complex proximal femoral fracture; $c, d$ ) Immediate post-op X-rays after PF-LCP fixation; e,f) $\mathrm{X}$-rays showing united fracture at one year follow-up; g,h) Clinical picture showing excellent functional outcome as well as the parker and palmar mobility score of $\mathbf{5 . 8}$ for the patient.

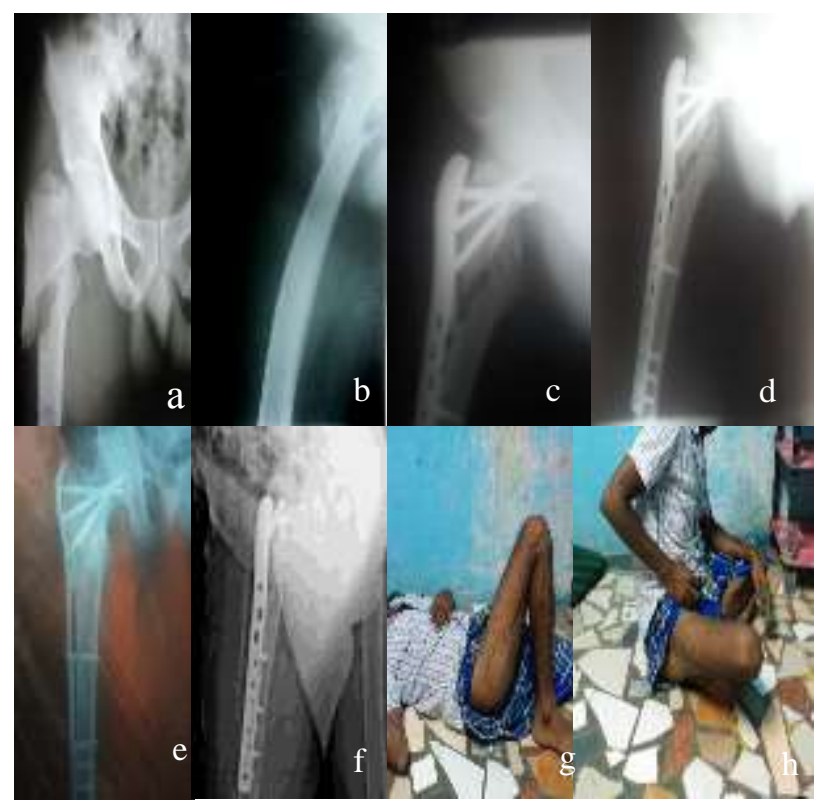

Figure 3: a,b) Pre-operative X-rays of 32 year male with right complex proximal femoral fracture; c,d) 3 month post-op X-rays after PF-LCP fixation showing delayed union and required additional bone grafting; e,f) X-rays showing good fracture union at end of one year; g,h)Clinical picture showing fair functional outcome and parker-palmar mobility score of 7.9 for the patient. 
Of the proximal femoral fractures, subtrochanteric fractures, took longer operative time, radiation exposure and had more bleeding than intertrochanteric fractures. Amongst the 18 cases 16 cases healed with no loss of position at the one year follow up check-up. There were two cases with delayed union which was severely comminuted, needed bone grafting. One case had superficial infection due to uncontrolled diabetes got settled. There were no cases of hip screw cutting the femoral head. There was no post-operative mortality in our study.

The average harris hip score was $85.5(83-94)$. The results were excellent in 10 cases $(55 \%)$, good in three cases $(17 \%)$, fair in five cases $(28 \%)$. There were no poor results. The assessment by Parker and Palmar mobility score was 7.6 (range 4-9).

\section{DISCUSSION}

Early operative treatment of proximal femoral fractures reduces both mortality and morbidity and reducing the risks of prolonged bed rest. The best treatment of these fractures remains controversial. ${ }^{16}$ The fixation method ranges from dynamic hip screw (DHS) in stable fractures and intra medullary devices in unstable fractures which has some theoretical advantage over DHS because they don't depend on the screw fixation of a plate to the lateral cortex which is a problem in a very osteoporotic bone. The failure rate in intramedullary devices ranges from 12.7 to $15 \%$ in various studies. ${ }^{17,18}$ As for the PFN, Fogagnolo et al found the intraopeartive technical or mechanical complication rate as high as $23.4 \% .{ }^{19}$ Uzun et al reported non-union $5.7 \%$ secondary varus displacement $25.7 \%$, screw cut-out $5.7 \%$, reverse Z-effect $14.3 \% .^{20}$ Ekstrom et al reported a lower complication rate of $8 \% .{ }^{21}$ In the current study, we found that the treatment of pertrochanteric fractures treated with PF-LCP could lower the complication rate than other treatment modalities described above. In our study, there were no cases of inter operative and technical complication. ${ }^{22}$ Other parameters such as operating time, operative blood loss, radiation exposure time and length of incision are better to those in previous studies using other devices. ${ }^{23-25}$

In our study, the union rate with proximal femoral fractures at the end of three months was $89 \%$, at the end of 6 months was $94 \%$ and had $100 \%$ union at one year follow up. No case had cut-out of the femoral head screw possibly due to mechanical advantage of three dimension and angular stable fixation by PF-LCP. The implant is biologically and biomechanically suitable in complex femoral fractures associated with osteoporosis. The PFLCP with the "kickstand" screw was reported to have similar biomechanical properties of 95-degree angle blade plate. PF-LCP locks the fracture in a position without controlled collapse, so varus collapse is avoided. The multiple locking screws increase the bone purchase in the femoral neck so it is appropriate for complex proximal femoral fracture fixation even in osteoporotic bone.

Good preoperative templating with good selection of appropriate implant and fracture must be adequately reduced and all three proximal femoral locking screws including the "kickstand" screw should be inserted to increase the mechanical strength of the construct. The indication for PF-LCP is narrower and used only in special situation. The main disadvantage of PF-LCP is open reduction which can result in increase blood loss and requires skilled technique. ${ }^{24,25}$

Our study shows PF-LCP is a good alternative for treating complex proximal femoral fractures. The complication rates are lower. So for treatment of complex femoral fractures is individualized based on patient assessment and experience of the operating team. Our study has several limitations as the sample size was small and we didn't differentiate trochanteric and subtrochanteric fractures. The PF-LCP provides good to excellent bone healing with a limited number of complications.

\section{ACKNOWLEDGEMENTS}

Author would like to thank all patients for their cooperation in study.

\section{Funding: No funding sources \\ Conflict of interest: None declared \\ Ethical approval: Not required}

\section{REFERENCES}

1. Nieves JW, Bilezikian JP, Lane JM, Einhorn TA, Wang Y, Steinbuch M, et al. Fragility fractures of the hip and femur: incidence and patient characteristics. Osteoporos Int. 2010;21(3):399-408.

2. Dobbs RE, Parvizi J, Lewallen DG. Perioperative morbidity and 30 day mortility after intertrochanteric hip fractures treated by internal fixation or arthoplasty. J Arthoplasty. 2005;20(8):963-6.

3. Wolfgang GL, Bryant MH, Oneill JP. Treatment of intertrochanteric fracture of the femur using sliding screw plate fixation. Clin Orthop Relat Res. 1982;163:148-58.

4. Kokoroghiannis C, Aktselis I, Deligeorgis A, Fragkomichalos E, Papadimas D, Pappadas I. Evolving concepts of stability and intermedullary fixation of intertrochanteric fractures-a review. Injury. 2012;43(6):686-93.

5. Boldin C, Seibert FJ, Fankhauser F. The proximal femoral nail (PFN)- a minimal invasive treatment of unstable proximal femoral fractures a prospective study of 55 patients with a follow up of 15 months. Acta Orthop Scand. 2003;74:53-8. 
6. Stern R. Are there advances in the treatment of extracapsular hip fractures in the elderly? Injury. 2007;38(3):77-87.

7. Haidukewych GJ. Intertrochanteric fracture: ten tips to improve results. J Bone Joint Surg Arm. 2009;91:712-9.

8. Gotfried Y. The lateral trochanteric wall: a key element in the reconstruction of ubstable pertrochanteric hip fractures. Clin Orthop Relat Res. 2004;425:82-6.

9. Palm H, Jacobsen S, Sonne HS, Gebuhr P. Hip fracture study group integrity of the lateral femoral wall in intertrochanteric hip fractures: an important predictor of a reoperation. J Bone Joint Surg Am. 2007;89(3):470-5.

10. Kinast C, Bolhofner BR, Mast JW, Ganz R. Subtrochanteric fractures of the femur results of treatment with the 95 degrees condylar blade-plate. Clin Orthop Relat Res. 1989;238:122-30.

11. Ozkan K, Türkmen I, Sahin A, Yildiz Y, Erturk S, Soylemez MS. A biomechanical comparison of proximal femoral nails and locking proximal anatomic femoral plates in femoral fracture fixation A study on synthetic bones. Indian $\mathbf{J}$ Orthop 2015;49:347-51.

12. E.A. Hasenboehler ,J.F. Adudelo, S.J.Morgan , W.R. Smith, D.J. Hak, P.F.Stahel. Treatment of complex proximal femoral fractures with the proximal femur locking compression plate. Orthopedics,30(8)(2007),pp.618-623.

13. Egol KA, Kubiak EN, Fulkerson E, Kummer FJ, Koval KJ. Biomechanics of locked plates and screws. J Orthop Trauma. 2004;18(8):488-493.

14. Jensen JS. Classification of trochanteric fractures. Acta Orthop Scand. 1980;51(5):803-10.

15. Nilsdotter A, Bremander A. Measures of hip functions and symptoms. Arthritis Care Research. 2011;63(11):200-7.

16. Jensen JS, Holm SS, Tondevold E. Unstable trochanteric fractures a comparative analysis of four methods of internal fixation. Acta Orthop Scand. 1980;51(6):949-62.

17. Saarenpaa I, Heikkinen J, Ristiniemi J. Functional comparison of the dynamic hip screw and the gamma locking nail in intertrochanteric hip fractures: a matched-pair study of 268 patients. Int Orthop. 2009;33(1):255-60.

18. Sehat K, Baker KP, Pattison G. The use of the long gamma nail in proximal femoral fractures. Injury. 2005;36(11):1350-4.

19. Fogagnolo F, Kfuri M, Paccola C. Intramedullary fixation of pertrochanteric hip fractures with the short AO-ASIF proximal femoral nail. Arch Orthop Trauma Surg. 2004; 124:31-7.

20. Uzun M, Erturer E, Ozturk I. Long-term radiographic complications following treatment of unstable intertrochanteric femoral fractures with the proximal femoral nail and effects on functional results. Acta Orthop Traumatol Turc. 2009;43(6):457-63.

21. Ekstrom W, Karlsson CT, Larsson S. Functional outcome in treatment of unstable trochanteric and subtrochanteric fracture with the proximal femoral nail and the medoff sliding plate. J Orthop Trauma. 2007;21(1):18-25.

22. Suckel AA, Dietz K, Wuelker N, Helwig P. Evaluation of complications of three different types of proximal extra-articular femur fractures: differences in complications, age, sex and surviving rates. Int Orthop, 2007;31:689-95.

23. Zha GC, Chen ZL, Qi XB, Sun JY. Treatment of pertrochanteric fractures with a proximal femur locking compression plate. Injury. 2011;42(11):1294-9.

24. Lee WT, Murphy D, Kagda FHY, Thambiah J. Proximal femoral locking compression plate for proximal femoral fractures. J Orthopaedic Surg. 2014;22(3):287-93.

25. Hasenboehler EA, Agudelo JF, Morgan SJ, Smith WR, Hak DJ, Stahel PF. Treatment of complex proximal femoral fractures with the proximal femur locking compression plate. Orthopedia. 2007;30(8):618-23.

Cite this article as: Govindasamy $\mathrm{R}$, Gnanasundaram R, Kasirajan S, Meleppuram JJ, Archit K. Proximal femur locking compression plate in complex proximal femoral fractures: a retrospective analysis. Int J Res Orthop 2016;2:104-8. 